\title{
Effect of Ethanol Leaf Extract of Simarouba glauca on Induced Dyslipidemia and Oxidative Stress
}

\author{
*Osagie-Eweka ${ }^{1}$, S. D., Orhue ${ }^{1}$, N. E. J. and Eric Omogbai², E.I \\ 1 Department of Biochemistry, Faculty of Life Sciences, University of Benin. Benin City. Nigeria. \\ 2Department of Pharmacology and Toxicology, Faculty of Pharmacy, University of Benin, Benin City, Nigeria \\ *Correspondence: davies.osagie-eweka@uniben.edu; https://doi.org/10.52417/njls.v11i1.12
}

\begin{abstract}
Biologically active compounds with pharmacological potentials have been reported in Simarouba glauca; these compounds have shown interactions with biological molecules, hence this study. This study focused on long-term effect of ethanol leaf extract of Simarouba glauca (EESG) on lipoproteins and oxidative stress biomarkers in male Wistar rats. Oral administration of EESG was conducted according to the guidelines of organization for economic co-operation and development (OECD), No. 425 using a total of twenty-four (24) male Wistar rats, divided into four groups of six rats each. Test rats were given EESG at doses of 500, 1000 and $2000 \mathrm{mg} / \mathrm{kg}$ body weight respectively daily for thirty (30) days. At the end of the study, the rats were fasted overnight and sacrificed; relevant biochemical analyses were evaluated. Data were statistically analyzed with the Graphpad prism ${ }^{\circledR}$, version 7. The data show marked reduction and increase $(P<0.05)$ in $\mathrm{HDL}$-cholesterol and TG respectively, at all doses; significant increase $(P<0.05)$ in LDL-cholesterol at EESG 500 and $1000 \mathrm{mg} / \mathrm{kg}$. Furthermore, the data obtained however indicated significant $(P<0.05)$ elevation in heart MDA level at $500 \mathrm{mg} / \mathrm{kg}$. The liver and kidney CAT activity were elevated $(P<0.05)$ at EESG $1000 \mathrm{mg} / \mathrm{kg}$; 500 and $2000 \mathrm{mg} / \mathrm{kg}$ respectively. Liver and Kidney SOD activity were elevated $(P<0.05)$ at $2000 \mathrm{mg} / \mathrm{kg}, 500$ and $1000 \mathrm{mg} / \mathrm{kg}$ respectively. The Liver GSH-PX was elevated $(P<0.05)$ at $2000 \mathrm{mg} / \mathrm{kg}$. The findings of the study showed that oral administration of EESG at high doses resulted to dyslipidemia. The marked increases in the endogenous defense enzyme system may have resulted from cytochrome $P-450 / N A D P H$ Oxidase induced oxidative stress linked to xenobiotic metabolism.
\end{abstract}

Keywords: Simarouba glauca; Wistar rats, Toxicity, Dyslipidemia, Oxidative stress.

\section{Introduction}

Lipid play important roles in the human body such as hormones, aid in digestibility, provide energy, storage and metabolic fuels, act as functional and structural components of bio-membranes, form insulation; to enable nerve conduction and prevent heat loss (Trinder, 1969), amongst others. Plasma Low-Density Lipoprotein Cholesterol $(\mathrm{LDL}-\mathrm{C})$ is a class of plasma lipoprotein that is regarded as bad cholesterol. A strong pathological correlation between LDL-C and cardiovascular complications have long been established (Cesare et al., 2005). It has also been reported that oxidized LDL-C resulting from oxidative stress can be injurious to vascular endothelium rendering it dysfunctional (Steinberg, 1997). Epidemiological studies have also reportedly implicated elevated triglycerides and reduced HDL in cardiovascular diseases (Hokanson and Austin, 1996; Nordestgaard and Varbo, 2014). Several toxicological studies have reported the effect of a number of medicinal plant supplements on lipid metabolism ranging from severe dyslipidemia to hypolipidemia at varying doses (Patrick-Iwuanyanwu et al., 2012; Haza et al., 2016; Ogbonnia et al., 2010; Adebayo et al., 2006; Perez et al., 1999).

In a related study, the prooxidant action of phenoxyl radical generated from the electron-donating action of phenolic compounds have been strongly implicated in inducing oxidative stress (Sakihama et al., 2002). That is, medicinal herbal supplements that contain phenolics may generate phenoxyl radicals as the primary oxidized product (Sakihama et al., 2002), capable of initiating oxidative damage to tissues.

Several phytochemicals such as alkaloids, anthraquinone glycosides, pyrrolizidine alkaloidshave been implicated in toxicological studies (George, 2011; Rowin and Lewis, 1996; Becker et al., 1996). Simarouba glauca, commonly known as "Paradise tree" or "Laxmitaru" belongs to the family Simaroubaceae (Patil and Gaikwad, 2011). Simarouba glauca has a long history of herbal medicine application given its many documented pharmacological properties (Patil and Gaikwad, 2011). The stem-bark and leaf of $S$. glauca contain triterpenes useful in curing amoebiasis, diarrhea and malaria (Joshi and Joshi, 2002). Chemicals present in leaf, fruit, pulp and seed of $S$. glauca have been reported to possess analgesic, antimicrobial, antiviral, astringent, emmenagogue, stomachic, tonic, vermifuge properties (Joshi and Joshi, 2002). Figure 1 shows Simarouba glauca growing in a natural habitat at Cercobela ${ }^{\circledR}$ farms, Ubiaja.

\section{Materials and Methods}

Collection of $S$. glauca leaves and preparation of ethanol extract Leaves of $S$. glauca were obtained (harvested) from Cercobela Farms ${ }^{\circledR}$, Ubiaja, Esan South East Local Government Area of Edo State, Nigeria. A Fresh plant specimen was authenticated and a voucher specimen deposited at the Department of Plant Biology and Biotechnology Herbarium, University of Benin, Benin City, Nigeria, with voucher No. $\mathrm{UBH}_{\mathrm{s}} 382$. The leaves were rinsed with tap water and air-dried in the Laboratory at the Department of Biochemistry for twenty-eight (28) days at room temperature. Leaves were pulverized and sieved off a mesh to obtain fine particles at the Department of Pharmacognosy, Faculty of Pharmacy, University of Benin. Five hundred grams (500 g) of the leaf powder was soaked in a $2.5 \mathrm{~L}$ ethanol $(99.5 \%$ purity and analytical grade) and stirred at intervals for 24 hours. The procedure was repeated for another 24 hours to obtain filtrate that was freezedried to obtain dried ethanol extract as previously reported by OsagieEweka et al. (2016).

Reagents and test kits

Total Cholesterol kit, Triglyceride kit, HDL-Cholesterol kit, all from Randox Laboratory (UK). The chemicals used to prepare a working reagent included thiobarbituric acid (TBA), glacial acetic acid, $0.05 \mathrm{M}$ 


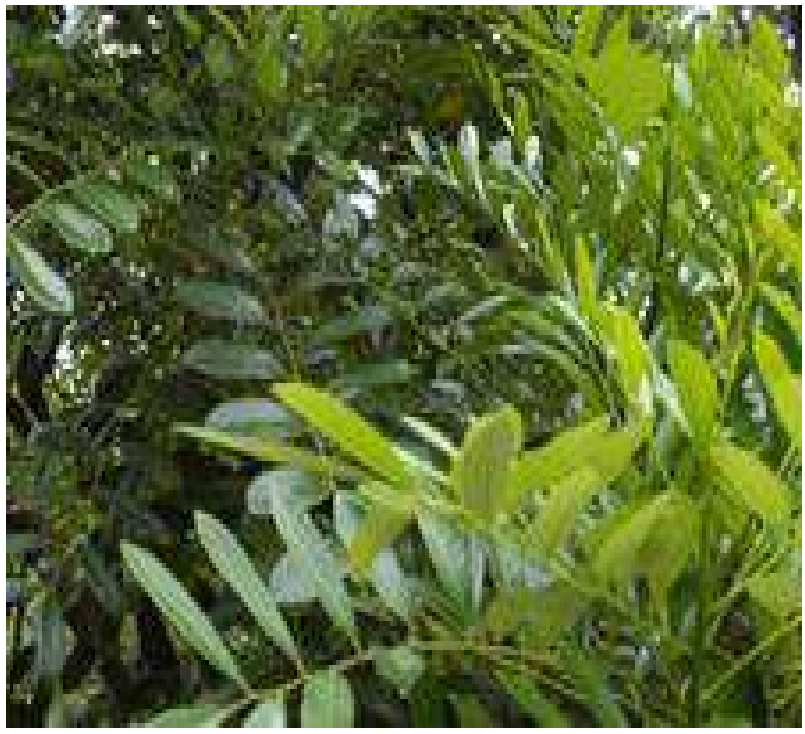

Fig. 1. Young Paradise Tree (S. glauca) growing in Cercobela Farms $®$ (Osagie-Eweka Photo Library, 2015).

Phosphate buffer at $\mathrm{p}^{\mathrm{H}} 7.0, \mathrm{H}_{2} \mathrm{SO}_{4}, \mathrm{KMnO}_{4}$, carbonate buffer, 5,5'dithio-bis-(2-nitrobenzoic acid) (DTNB), $100 \mathrm{mM}$ potassium phosphate buffer at $\mathrm{p}^{\mathrm{H}}$ 6.0, $\mathrm{H}_{2} \mathrm{O}_{2}$, pyrogallol, distilled $\mathrm{H}_{2} \mathrm{O}$ and deionized $\mathrm{H}_{2} \mathrm{O}$.

Experimental animals

A total of 24 male Wistar rats weighing between 184 and $200 \mathrm{~g}$ were used for the study. The animals were housed in metabolic cages; were fed normal commercial pelleted diet (Livestock Feeds ${ }^{\circledR}$ ), water ad libitum and maintained under laboratory conditions of $12 \mathrm{~h}$ light/12 dark cycle with a two-week acclimatization prior to commencement of studies. The research was conducted in accordance with the internationally accepted guidelines for laboratory animal use.

\section{Oral Administration of EESG}

The study was conducted as prescribed in the OECD (2008), No. 425 test guidelines earlier described by Rout et al. (2014) and Oliveira et al. (2016). A total of twenty-four (24) male Wistar rats were utilized in the study and were allowed access to food and drinking water $a d$ libitum. The rats were distributed into four (4) groups of $n=6$. Test animals received 500,1000 and $2000 \mathrm{mg} / \mathrm{kg}$ body weight respectively of EESG daily for thirty (30) days orally administered with gavage (oral gastric tube, OGT), while the control group received only rat pellets and water.

Collection of data and specimen

At the end of the study, the rats were fasted overnight, anesthetized using a chloroform saturated chamber and sacrificed. The thoracic and abdominal regions were opened up and blood was withdrawn from the hepatic portal vein and (or) thoracic aorta using a $5 \mathrm{ml}$ syringe and emptied into a $5 \mathrm{~mL}$ heparinized specimen bottle. The blood was then centrifuged at 3,500 rpm for 10 minutes to obtain a clear supernatant (Plasma) that was stored at $-18^{\circ} \mathrm{C}$ until required for relevant biochemical analyses, conducted within a few days.

Biochemical analyses

Lipid profile tests which include Total Cholesterol, HDL-C, TG and LDL$C$ were done using colorimetric methods described by Roeschlaw et al. (1974), Jacobs and Van Denmark (1960) and Friedewald et al. (1972) respectively with the aid of commercially available test kits, (Randox Laboratories (United Kingdom). The oxidative stress status was evaluated by assaying the levels of MDA, CAT and SOD activities, GSH and GSHPX according to the methods reported by Gutteridge and Wilkins (1982), Cohen et al. (1970) Misra and Fridovich (1972), Ellman (1959), Chance and Maehly (1955) respectively.

\section{Statistical analyses}

Data obtained from the study are expressed as mean and standard deviation (mean $\pm \mathrm{SD}$ ) where applicable. Statistical differences between means of test group were evaluated by one-way analysis of variance (ANOVA) while the post-hoc comparison tests were carried out using the Tukey's multiple comparison test. Differences in means were considered significant at $P<0.05$ and not significant at $P>0.05$. All statistical analyses were conducted using GraphPadprism ${ }^{\circledR}$, version 7.

\section{Results}

Effect of oral administration of EESG on TC, TG and lipoproteins in Wistar rats

The data presented in Fig. 2 shows marked reduction $(P<0.05)$ in plasma total cholesterol at EESG dose of $2000 \mathrm{mg} / \mathrm{kg}$ relative to the control. There was marked reduction and elevation $(P<0.05)$ in highdensity lipoprotein cholesterol (HDL-C) and triglycerides (TG) at all doses respectively compared to the control. The low-density lipoprotein cholesterol (LDL-C) was markedly elevated $(P<0.05)$ at EESG doses of 500 and $1000 \mathrm{mg} / \mathrm{kg}$ relative to the control, but was nonsignificantly reduced at $2000 \mathrm{mg} / \mathrm{kg}$ body weight.

Effect of oral administration of EESG on oxidative stress biomarkers in Wistar Rats

The data presented in Fig. 3 show there were no significant differences $(P>0.05)$ in liver and kidney malondialdehyde (MDA) levels at all doses compared to the control whereas there was marked elevation ( $P$ $<0.05$ ) in heart MDA level at EESG dose of $500 \mathrm{mg} / \mathrm{kg}$ and reduction $(P<0.05)$ in heart MDA levels at EESG doses of 1000 and 2000 $\mathrm{mg} / \mathrm{kg} \mathrm{mg} / \mathrm{kg}$ respectively compared to the control. The data presented in Fig. 4 show marked elevation $(P<0.05)$ in liver catalase (CAT) activity at EESG dose of $1000 \mathrm{mg} / \mathrm{kg}$, significant increase $(P<0.05)$ in kidney CAT activity at EESG doses of 500 and $2000 \mathrm{mg} / \mathrm{kg}$; increase in heart CAT activity at EESG dose of $1000 \mathrm{mg} / \mathrm{kg}(P>0.05)$ and decreases in heart CAT activity at EESG doses of 500 and $2000 \mathrm{mg} / \mathrm{kg}$ $(P>0.05)$ relative to the control. Figure 5 shows marked elevation $(P$ $<0.05$ ) in liver superoxide dismutase (SOD) activity at EESG dose of $2000 \mathrm{mg} / \mathrm{kg}$, elevation $(P<0.05)$ in kidney SOD activity at EESG doses of 500 and $1000 \mathrm{mg} / \mathrm{kg}$; no significant difference in kidney SOD activity at EESG dose of $2000 \mathrm{mg} / \mathrm{kg}$ body weight compared to the control. However, a reduction $(P>0.05)$ in heart SOD activity at EESG doses of 500 and $1000 \mathrm{mg} / \mathrm{kg}$ compared to the control was observed. Figures $6 \mathrm{a}$ and $6 \mathrm{~b}$ revealed there were no significant alterations $(P>$ 0.05 in plasma, liver and heart glutathione (GSH) levels respectively at all doses relative to the control group. Figure 7 a revealed no significant difference $(P>0.05)$ in plasma glutathione peroxidase (GSH-PX) activity at all doses relative to the control. Figure $7 \mathrm{~b}$ showed marked increase $(P<0.05)$ in liver GSH-PX activity at EESG dose of $2000 \mathrm{mg} / \mathrm{kg}$; whereas there was significant reduction $(P<0.05)$ in heart GSH-PX activity at all doses compared to the controls. 


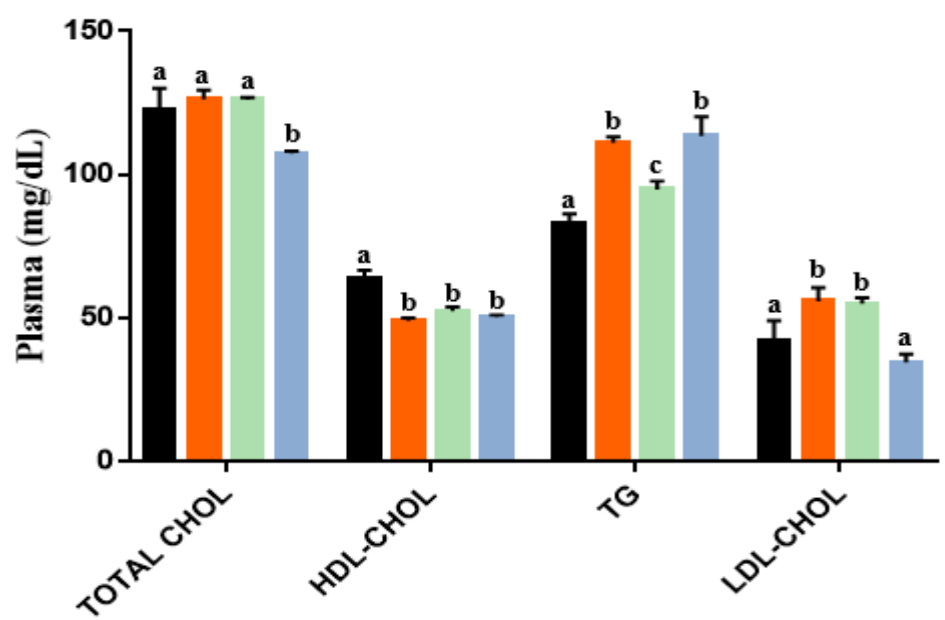

CONTROL

EESG. 500 mg/kg BWT

EESG. $1000 \mathrm{mg} / \mathrm{kg}$ BWT

EESG. $2000 \mathrm{mg} / \mathrm{kg}$ BWT

Fig. 2. Effect of varying doses of ethanol Leaf Extract of $S$. glauca (EESG) on Plasma TC, HDL-C, TGand LDL-C of Male Wistar Rats after 30 days. Data with similar lower-case alphabets are not significantly different $(p>0.05)$; data with different lower-case alphabets are significantly different $(p<0.05)$. Data are presented as Mean \pm SD.

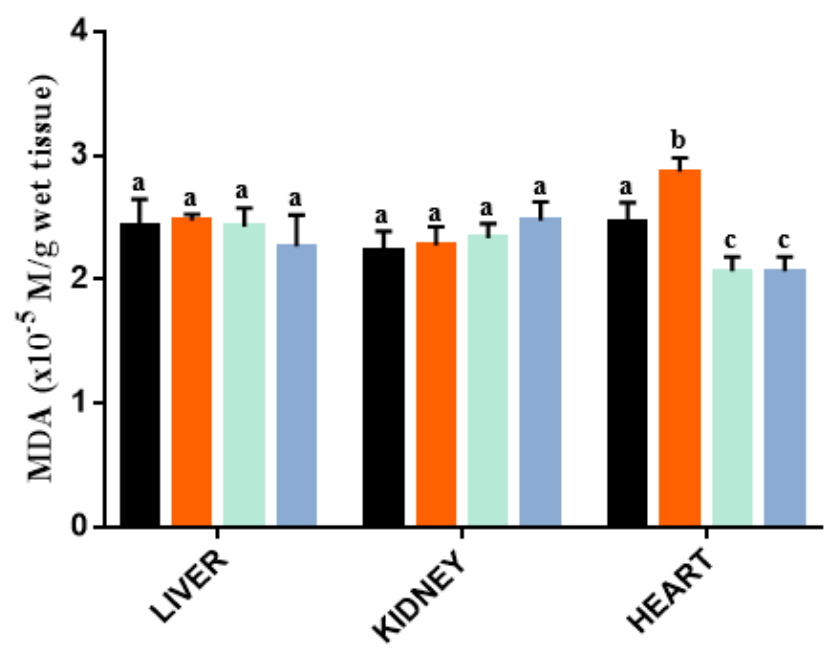

CONTROL

EESG. $500 \mathrm{mg} / \mathrm{kg}$ BWT

EESG. $1000 \mathrm{mg} / \mathrm{kg}$ BWT

EESG. $2000 \mathrm{mg} / \mathrm{kg}$ BWT

Fig. 3. Effect of varying doses of EESG on Liver, Kidney and Heart MDA levels of Male Wistar Rats after 30 days.

Data with similar lower-case alphabets are not significantly different $(p>0.05)$; data with different lower- case alphabets are significantly different $(p<0.05)$. Data are presented as Mean \pm SD.

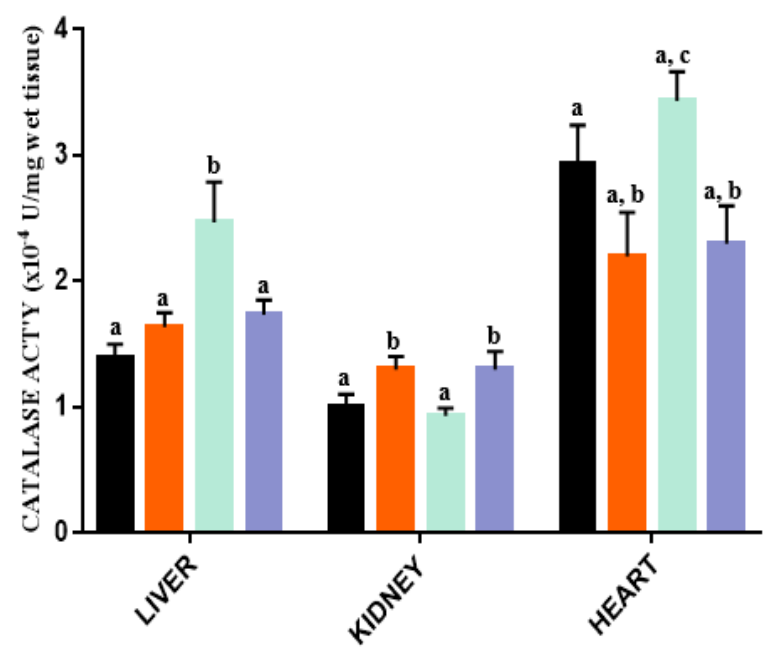

CONTROL

EESG. $500 \mathrm{mg} / \mathrm{kg}$ BWT

EESG. $1000 \mathrm{mg} / \mathrm{kg}$ BWT

EESG. 2000 mg/kg BWT

Fig. 4. Effect of varying doses of EESG on Liver, Kidney and Heart CAT activity of Male Wistar Rats after 30 days. Data with similar lower-case alphabets are not significantly different $(p>0.05)$; data with different lower- case alphabets are significantly different $(p<0.05)$. Data are presented as Mean \pm SD. 


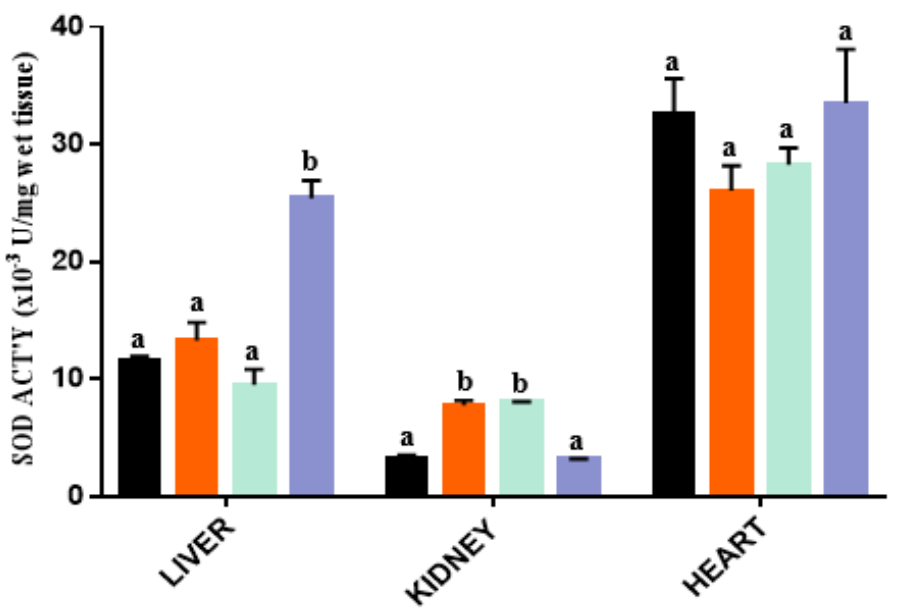

CONTROL

EESG. $500 \mathrm{mg} / \mathrm{kg} \mathrm{BWT}$

EESG. $1000 \mathrm{mg} / \mathrm{kg} \mathrm{BWT}$

EESG. $2000 \mathrm{mg} / \mathrm{kg}$ BWT

Fig. 5. Effect of varying doses of EESG on Liver, Kidney and Heart SOD activity of Male Wistar Rats after 30 days. Data with similar lower-case alphabets are not significantly different $(p>0.05)$; data with different lower- case alphabets are significantly different $(p<0.05)$. Data are presented as Mean \pm SD.

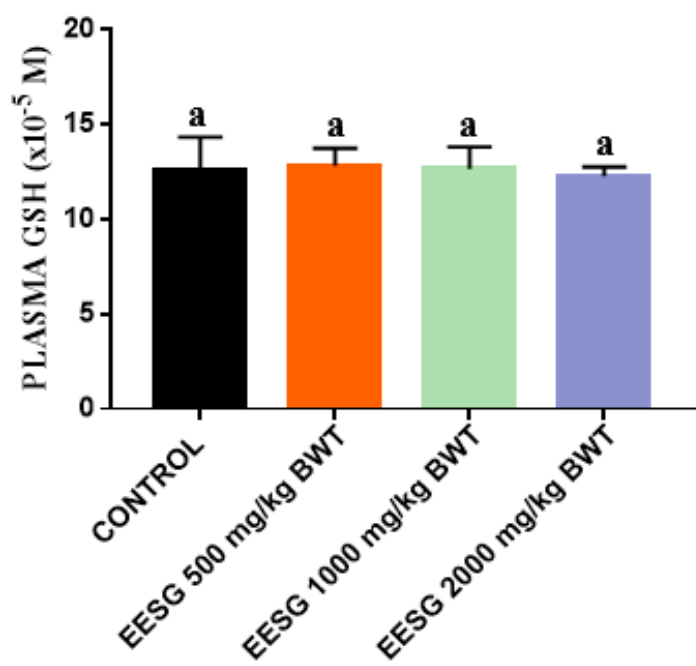

CONTROL

EESG $500 \mathrm{mg} / \mathrm{kg}$ BWT

EESG $1000 \mathrm{mg} / \mathrm{kg}$ BWT

EESG $2000 \mathrm{mg} / \mathrm{kg}$ BWT

Fig. 6a. Effect of varying doses of EESG on Plasma GSH level of Male Wistar Rats after 30 days.

Data with similar lower-case alphabets are not significantly different $(p>0.05)$; data with different lower- case alphabets are significantly different $(p<0.05)$. Data are presented as Mean \pm SD.

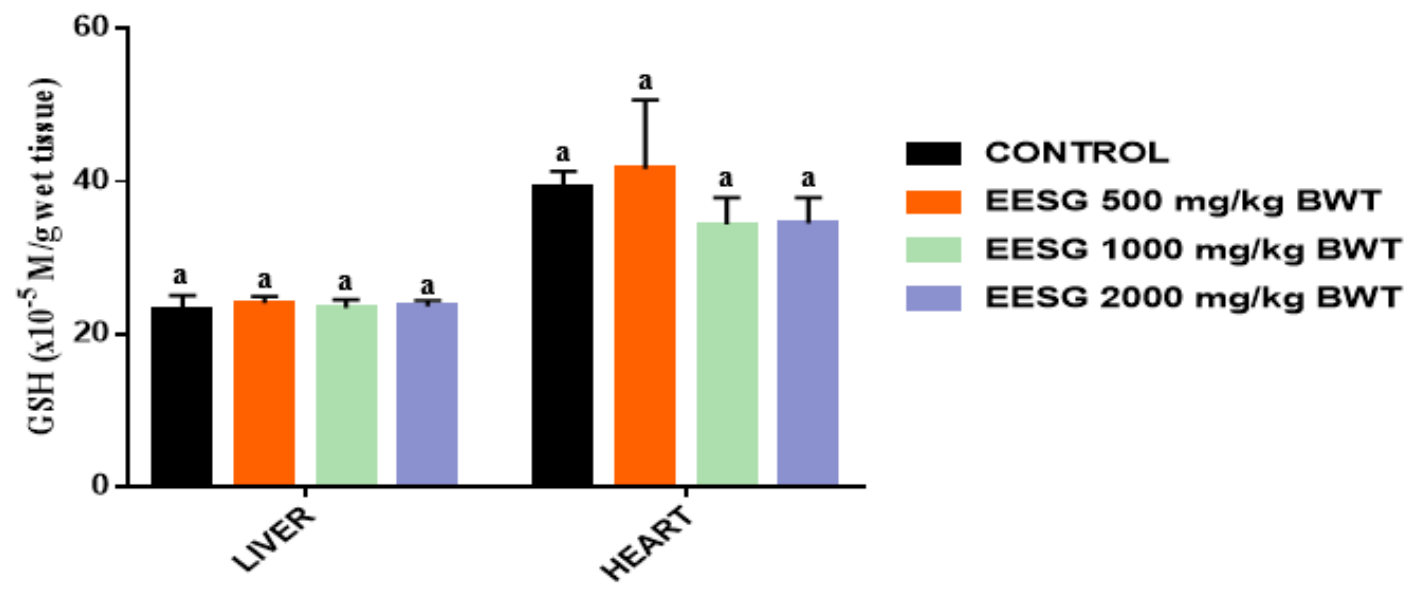

Fig. 6b. Effect of varying doses of EESG on Liver and Heart GSH levels of Male Wistar Rats after 30 days.

Data with similar lower-case alphabets are not significantly different $(p>0.05)$; data with different lower- case alphabets are significantly different $(p<0.05)$. Data are presented as Mean \pm SD. 


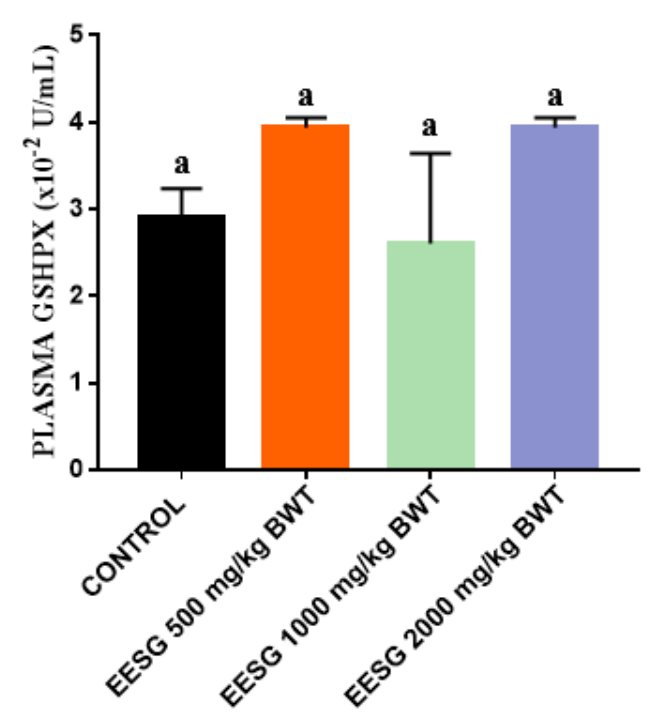

- CONTROL

EESG $500 \mathrm{mg} / \mathrm{kg}$ BWT

EESG $1000 \mathrm{mg} / \mathrm{kg}$ BWT

EESG 2000 mg/kg BWT

Fig. 7a. Effect of varying doses of EESG on Plasma GSHPX activity of Male WistarRats after 30 days.Data with similar lower-case alphabets are not significantly different $(p>0.05)$; data with different lower- case alphabets are significantly different $(p<0.05)$. Data are presented as Mean \pm SD.

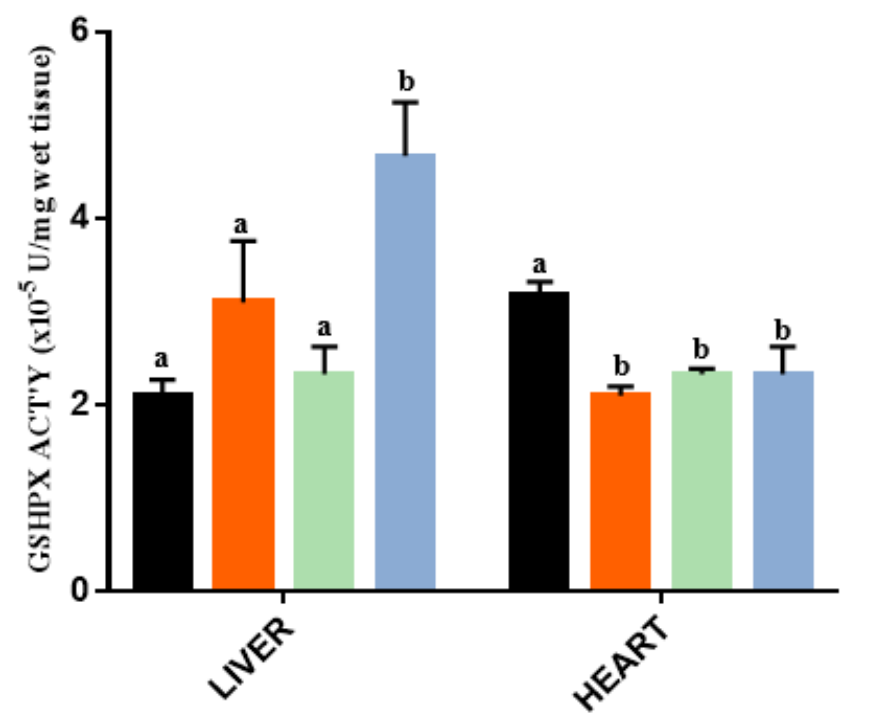

\section{CONTROL \\ EESG $500 \mathrm{mg} / \mathrm{kg} \mathrm{BWT}$ EESG $1000 \mathrm{mg} / \mathrm{kg} \mathrm{BWT}$ EESG $2000 \mathrm{mg} / \mathrm{kg}$ BWT}

Fig. 7b. Effect of varying doses of EESG on Liver and Heart GSHPX activities of Male WistarRats after 30days. Data with similar lower-case alphabets are not significantly different $(p>0.05)$; data with different lower- case alphabets are significantly different $(p<0.05)$. Data are presented as Mean \pm SD.

\section{Discussion}

Lipids are a vital part of the metabolic process. It forms an integral part of the cell membrane. Alteration in lipid biomarkers may strongly indicate some levels of toxicity, probably initiated by external factors and (or) alteration in internal regulatory mechanism. Lipid oxidation, particularly oxidized LDL-cholesterol elicit plaques on vascular tissues endothelium initiating the onset of cardiovascular disease and oxidative damage resulting in endothelium dysfunction and nitric oxide insufficiency. Wiztum and Steinberg (1991) reported that oxidized lipids activate alterations observed as dyslipidemia and (or) hyperlipidemia which in-turn orchestrates cardiovascular disease and other related conditions.

A number of studies relating to the application of medicinal plants have reported findings on lipid-lowering effect of these active compounds on the liver lipid metabolism, circulatory system and at the modulatory intracellular signaling pathways and transcriptional activities (Kun-Ho et al., 2016; Koo and Noh, 2007; Ahmida and Abuzogaya, 2009).

In the present study, oral administration of EESG did not trigger elevation in plasma TC as shown in fig. 2. However, there were marked increases in plasma TG, LDL-cholesterol and marked decrease in plasma HDL-cholesterol. Nordestgaard and Varbo (2014) in an epidemiological study reported that for an unexplained reason, it was observed that marked increase in plasma TG and marked reduction in HDL-cholesterol strongly indicate a link with cardiovascular disease. Although, it is not unlikely that the observed increase in plasma triglycerides and LDL-cholesterol may have resulted from chylomicrons formed from dietary lipids due to the inability of the liver to effectively metabolize the lipids and synthesize bile salts. A previous article earlier published from our laboratory revealed that oral administration of EESG at similar doses resulted in congestion and hepatic inflammation (Osagie-Eweka et al., 2020); this may well be responsible for the poor 
dietary cholesterol metabolism by the liver, hence elevations in plasma lipids. Furthermore, it is most likely that increase in glucose breakdown; coupled with increased pentose phosphate pathway activity can increase acetyl-CoA yield (precursor) for fatty acid synthesis. The data obtained from the present study differs from the reports of Kun-Ho et al. (2016), Koo and Noh (2007) and Ahmida and Abuzogaya (2009) where they published the lipid-lowering effect of a number of medicinal plants. Although, the plants may possess unrelated characteristics. The observed discrepancies may not be unconnected to the effect of EESG on the liver (Osagie-Eweka et al., 2020) due to the high free fatty acid oil content of simarouba glauca plant (Jena et al., 2010).

There are speculations that the application of medicinal plants and their active compounds such as phenolics may release prooxidants capable of eliciting oxidative damage to biomolecules such as lipids (Sakihama et al., 2002) which may consequently lead to lipid peroxidation, eliciting elevations in endogenous anti-oxidative stress enzymes. On the other hand, medicinal plants have been reported to enhance these antioxidant enzymes (Al-Sa'aidi et al., 2012). In the present study, the observed increase in TG and LDL-C did not directly result to oxidized LDL-C and as such, there was no obvious increase in the MDA level which is a known indicator of lipid damage. The enhanced liver and kidney SOD and CAT activities is indicative of EESG ability to stimulate increased synthesis of these protective enzymes.

\section{Conclusion}

The outcome of the study showed that EESG administered orally to experimental rat did not elicit lipid peroxidation; in fact, EESG stimulated endogenous antioxidant proteins.

\section{References}

Adebayo, A.H. Aliyu, R., Gatsing, D. and Garba LH. (2006). The effects of ethanolic leaf extract of Commiphora africana (Buseraceae) on lipid profile in rats. International Journal of Pharmacology 2(6): 618-622.

Ahmida, M.H. and Abuzogaya, M.H. (2009). The effects of oral administration of green tea and ginger extracts on serum and hepatic lipid content in rats fed a hyperlipidemic diet. Journal of Applied Sciences Research 8: 1709-1713.

Al-Sa'aidi, J.A.A., Alrodhan, M.N.A. and Ismael, A.K. (2012). antioxidant activity of $\mathrm{n}$-butanol extract of celery (Apium graveolens) seed in streptozotocin-induced diabetic male rats. Journal of Research in Pharmaceutical Biotechnology, 4(2): 24-29.

Becker, B.N., Greene, J., Evanson, J., Chidsey, G. and Stone W.J. (1996). Ginseng-induced diuretic resistance. Journal of American Medical Association 276(8): 606-607.

Cesare R, Sirtoli, C.R. and Fumagalli R. (2005). LDL-Cholesterol lowering or hdl-cholesterol raising for cardiovascular prevention: a lesson from cholesterol turnover studies and others. Journal of Atherosclerosis 186: 1-11.

Chance, B. and Maehly, A.C. (1955). Enzymatic assay of peroxidase. Methods in Enzymology 11: 773-775.

Cohen, G., Dembiec, D. and Marcus, J. (1970). Measurement of catalase activity in tissue extract. Journal of Analytical Biochemistry 34: 30-38.

Ellman, G.L. (1959). Tissue sulfhydryl groups. Archive of Biochemical Biophysics 82: 70-77.

Friedewald, W.T., Levy, R.I. and Fredrickson, D.S. (1972). Estimation of concentration of low-density lipoprotein cholesterol in plasma without the use of preparative centrifuge. Journal of Clinical Chemistry 18: 499-502.
George, P. (2011). Concerns regarding the safety and toxicity of medicinal plants: an overview. Journal of Applied Pharmaceutical Science 1(06): 40-44.

Gutteridge, J.M.C. and Wilkins, C. (1982). Copper dependent hydroxyl radical damage to ascorbic acid formation of thiobarbituric acid reactive products. FEBS Letter 137: 327-340.

Hokanson, J.E. and Austin, M.A. (1996). Plasma triglyceride level as a risk factor for cardiovascular diseases independent of highdensity lipoprotein cholesterol level: a meta-analysis of population-based perspective study. Journal of Cardiovascular Risk 1: 312-319.

Jacobs, N.J. and Van Denmark, P.J. (1960). Colorimetric Method for determination of triglycerides. Archive of Biochemistry and Biophysics 88: 250-255.

Jena, P.C. Raheman, H., Prasanna Kumar, G.V. and Machavaram, R. (2010). Biodiesel production from mixture of mahua and simarouba oils with high free fatty acids. Journal of Biomass and Bioenergy 34: 1108-1116.

Joshi, S. and Joshi, S. (2002). Oil Tree- Laxmitaru glauca University of Agricultural sciences, Bangalore and Indian Council of Agricultural Research, New Delhi, India P. 86.

Koo, S.I. and Noh, S.K. (2007). Green Tea as inhibitor of the intestinal absorption of lipids: potential mechanism for its lipidlowering effect. Journal of Nutritional Biochemistry 18(3): 179-183.

Kun-Ho, S., Glenn, E.B., Christina, T., Hong-Seok, K., Dong-Hyeon, K., Jung-Whan, C., Hyunsook, K. and Wallace, Y. (2016). Chardonnay grape seed flour ameliorates hepatic steatosis and insulin resistance via altered hepatic gene expression for oxidative stress, inflammation, and lipid and ceramide synthesis in diet-induced obese mice. Journal of PLOS ONE 11(12): 1-20.

Misra, H.P. and Fridovich, I. (1972). The Role of superoxide anion in the autoxidation of epinephrine and a simple assay for superoxide dismutase. Journal of Biological Chemistry 247(10): 3170-3175.

Nordestgaard, B.G. and Varbo A. (2014). Triglycerides and cardiovascular disease. Lancet 384: 625-635.

Ogbonnia, S.O., Mbaka, G.O., Anyika, E.N., Osegbo, O.M. and Igbokwe N.H. (2010). Evaluation of acute toxicity of hydro-ethanolic extract of Chromolaena odorata (L.) King and Robinson (Asteracea) in rats. Agricultural Biology Journal of North America 1: 859-65.

Oliveira, M.S., Fernandes, M.Z.L.C.M., Mineiro, A.L.B.B., Santos, R.F.D., Viana, G.E.N., Coelho, J.M., Ribeiro, S.M., Cunha, A.P.G.P., Costa, J.F. and Fernandes, R.M. (2016). Toxicity effects of ethanol extract of Simarouba versicolor on reproductive parameters in female Wistar rats. African Journal of Biotechnology 15(8): 221-235.

Organisation for Economic Co-operation and Development. Guidance Document on Acute Oral Toxicity Testing OECD Environment, Health and Safety Publications, Series on Testing and Assessment 29 (Online) (2008), Available from: https://ntp.niehs.nih.gov/iccvam/suppdocs/feddocs/oecd/o ecd-gd129.pdf (Accessed on 23rd September, 2019).

Osagie-Eweka, SD.E., Orhue, N.E.J. and Ekhaguosa, D.O. (2016). Comparative phytochemical analyses and in-vitro antioxidant activity of queous and ethanol extracts of Simarouba glauca (Paradise Tree). European Journal of Medicinal Plants 13(3): 1-11. 
Osagie-Eweka, SD.E., Orhue, N.E.J., Omogbai, E.K.I. and Amaechina, F.C. (2020). Oral acute and sub-chronic toxicity assessment of ethanol leaf extract of Simarouba glauca. International Journal of Biochemistry Research and Review 29(8): 81100.

Patil, M.S. and Gaikwad, D.K. (2011). A critical review on medicinally important oil yielding plant Laxmitaru (Simarouba glauca DC) Journal of Pharmaceutical Sciences and Research 3(4): 1195-1213.

Patrick-Iwuanyanwu, K.C., Amadi, U., Charles, I.A. and Ayalogu E.0. (2012). Evaluation of acute and sub-chronic oral toxicity study of baker cleansers bitters -a polyherbal drug on experimental rats. EXCL/ Journa/ 11: 632-640.

Perez, C., Canal, JR., Campillo, JE., Romero, A. and Torres MD. (1999). Hypotriglyceridaemic activity of fiscus caarica leaves in experimental hypertriglyceridaemic rats. Journal of Phytotherapy Research 13: 188-191.

Roeschlau, P., Bernt, E. and Gruber, J.W. (1974). Enzymatic procedure for cholesterol determination. Journal Clinical Chemistry and Clinical Biochemistry 12: 403.

Rout, P.K., Rao, Y.R., Jena, K.S., Sahoo, D. and Ali, S. (2014). Safety evaluation of Simarouba glauca seed fat. Journal of Food Science Technology 51(7): 1349-1355.
Rowin, J., and Lewis S.L. (1996). Spontaneous bilateral subdural hematomas associated with chronic Ginkgo Biloba ingestion. Journal of Neurology 46: 1775-1776.

Sakihama, Y., Cohen, M.F., Grace, S.C. and Yamasaki, H. (2002). Plant phenolic antioxidant and prooxidant activities: phenolicsinduced oxidative damage mediated by metals in plants. Journal of Toxicology 177: 67-80.

Steinberg, D. (1997). Low-density lipoprotein oxidation and its pathological significance. Journal of Biological Chemistry 272: 20963-20966.

Trinder P. (1969). Metabolic Importance of Lipid. Annals of Clinical Biochemistry 6 P. 24.

Witztum, J.L. and Steinberg, D. (1991). Role of oxidized low-density lipoprotein in atherogenesis. Journal of Clinical Investigation 88: 1785-1792

Zaza, H.V., Tra Bi Irié, O., Gnahoué, G, Kouangbé, M.A., Kra, K.A.M. and N'Guessan J.D. (2016). Oral toxicity study of $x 42$ fraction of Terminalia ivorensis A.Chev. (Combretaceae) in rats. International Journal of Pharmacognosy and Phytochemical Research 8(12): 1913-1919. 